\title{
KEPATUHAN KUNJUNGAN NIFAS TERHADAP PENGETAHUAN MANAJEMEN LAKTASI PADA IBU NIFAS DI WILAYAH KERJA PUSKESMAS SEBENGKOK KOTA TARAKAN
}

\author{
Gusriani $^{1}$, Nur Indah Noviyanti ${ }^{2}$, Agus Purnamasari ${ }^{3}$ \\ 1,2,3 Jurusan Kebidanan Fakultas Ilmu Kesehatan Universitas Borneo Tarakan \\ *Email : nurindah@borneo.ac.id
}

\begin{abstract}
Abstrak
Kunjungan nifas merupakan salah satu upaya pemerintah dalam menurunkan angka kematian dan kesakitan ibu di Indonesia. Selain itu kunjungan nifas menjadi bagian dari peningktan derajat kesehatan ibu dan anak. Dengan adanya kunjungan nifas yang dilakukan ibu nifas sebanyak 3 kali selama masa nifas ibu akan mendapatkan edukasi dan promosi kesehatan dari bidan. Salah satu edukasi yang diberikan adalah manajemen laktasi. Menurut data kunjungan nifas di kota Kalimantan Utara yaitu, sebesar $85,1 \%$, sedangkan untuk pencapaian pemberian ASI dikalimantan utara 58,61 \% dan untuk kota Tarakan 63,1\%. Berdasarkan data dari Puskesmas Sebengkok Jumlah kunjungan Nifas pada bulan Januari sampai Maret 157 ibu nifas (17,1\%). Penelitian ini bertujuan untuk mengetahui hubungan antara kepatuhan kunjungan nifas terhadap pengetahuan manajemen laktasi. Jenis penelitian ini adalah analitik dengan pendekatan cross sectional. Populasi dalam penelitian ini adalah seluruh ibu nifas yang melakukan kunjungan Nifas di Pusksemas Sebengkok pada bulan Maret tahun 2020 sebanyak 45 ibu nifas. Teknik pengambilan sampel dalam penelitian ini menggunkan total sampling. Hasil penelitian menunjukan berdasarkan $X^{2}$ hitung $>X^{2}$ tabel dan $p<\alpha$ $=0.001$ yang artinya ada hubungan signifikan antara kepatuhan ibu melakukan kunjungan nifas dengan pengetahuan manajemen laktasi di Puskesmas Sebengkok Tarakan.
\end{abstract}

Kata Kunci : Kepatuhan, Kunjungan, Laktasi, Manajemen, Nifas

\begin{abstract}
Postpartum visits are one of the government's efforts to reduce maternal mortality and morbidity in Indonesia. The postpartum visit was part of an increase in the degree of maternal and child health. With the postpartum visit carried out mothers as many as 3 times during childbirth the mother will get education and health promotion from midwives. One of the education provided is lactation management. According to the postpartum visit data in the city of North Kalimantan, that is, at $85.1 \%$, while for the achievement of breastfeeding in North Kalimantan $58.61 \%$ and for the city of Tarakan 63.1\%. Based on data from Sebengkok Health Center Number of postpartum visits in January to March 157 postpartum mothers (17.1\%). This study aims to determine the relationship between compliance with puerperal visits to lactation management knowledge. This type of research is analytic with cross sectional approach. The population in this study were all postpartum mothers who visited Postpartum visits at Sebengkok Pusksemas in March 2020 as many as 45 postpartum mothers. The sampling technique in this study uses total sampling. The results showed based on X2 count $>X 2$ table and $p<\alpha=0.001$, which means that there is a significant relationship between maternal adherence to the puerperal visit with knowledge of lactation management at Sebengkok Tarakan Health Center.
\end{abstract}

Keywords: Compliance, Visitation, Lactation, Management, Postpartum 
Gusriani Dkk. Kepatuhan Kunjungan Nifas Terhadap Pengetahuan Manajemen Laktasi Pada

Ibu Nifas Di Wilayah Kerja Puskesmas Sebengkok Kota Tarakan. Journal Of Borneo Holistic

Health, Vol.3, No. 1 Juni 2020 Hal 69-74

\section{Pendahuluan}

Masa nifas merupakan masa pemulihan setelah bersalin sehingga organorgan reproduksi yang seorang ibu miliki dapat kembali seperti sebelum hamil. Proses ini berlangsung sampai 40 hari atau 6 minggu. Kunjungan nifas memiliki pengaruh besar terhadap pencegahan komplikasi masa nifas, yaitu perdarahan, pre eklampsia ringan, putting susu lecet, bendungan ASI, nyeri jahitan daerah perineum, dan kelaianan psikologis (Sokaraja \& Banyumas, 2016). Pada kunjungan nifas tidak hanya dilakukan pemeriksaan ibu nifas tetapi diberikan pendidikan kesehatan untuk meningkatkan derajat kesehatn ibu dan anak. Perubahan system reproduksi yang pada masa nifas akan mengalami involusi. Salah satu perubahan yamg terkadi adalaha perubahan pada bagian payudara ibu yang nantinya akan siap untuk memberikan nutrsi kepada bayinya.

Fokus asuhan yang dilakukan pada kunjungan nifas adalah pengkajian serta penyuluhan pendidikan kesehatan pada ibu nifas. Bidan sebagai tenaga kesehatn professional memberikan asuhan secara kritis sesuai dengan kebutuhan ibu nifas. Selain itu pada masa ini bidan akan memotivasi ibu untuk memberikan ASI eksklusif kepada bayinya. Kunjungan nifas yang berkualitas akan meningkatkan persepsi ibu nifas akan pentingnya melakukan kunjungan nifas ke Bidan sebagai suatu kebutuhan untuk meningkatkan derajat kesehatannya (Biomedika, 2019). Asuhan pada kunjungan nifas salah satunya adalah manajemen laktasi. Manajemen laktasi adalah bentuk usaha yang diberikan untuk memberikan dukungan ibu nifas dalam menyusui bayi. Pemberian ASI eksklusif kepada bayinya merupakan bagian dari peningkatan status gizi dimasyarakat (Astuti, 2014)

Pendidikan kesehatan yang diberikan oleh bidan pada saat melakukan kunjungan nifas berpengaruh besar terhadap keberhasilan dari menyusui ibu nifas. Dalam kunjungan nifas bidan memberikan pengetahuan terkait ASI, mulai cara menyusui, perawatan payurdara, masalahmasalah yang dapat terjadi di masa nifas, dan tentunya bidan selalu memberikan dukungan kepada ibu agar percaya diri memberikan gizi terbaik untuk bayinya melalui ASI (Nurbaeti \& Budi Lestari, 2013). Menurut data kunjungan nifas di kota Kalimantan Utara sebesar 85,1\%, sedangkan untuk pencapaian pemberian ASI dikalimantan utara 58,61\% dan untuk kota 
Gusriani Dkk. Kepatuhan Kunjungan Nifas Terhadap Pengetahuan Manajemen Laktasi Pada

Ibu Nifas Di Wilayah Kerja Puskesmas Sebengkok Kota Tarakan. Journal Of Borneo Holistic

Health, Vol.3, No. 1 Juni 2020 Hal 69-74

Tarakan 63,1\%. Berdasarkan data dari Puskesmas Sebengkok Jumlah kunjungan Nifas pada bulan Januari sampai Maret 157 ibu nifas $(17,1 \%)$. Melihat jumlah Pemberian ASI di di Kalimantan dan kota Tarakan cukup rendah, memberikan dampak kondisi gizi yang kurang baik, dan mengakibatkan bayi menjadi rentan terhdap beberapa penyakit infeksi seperti diare (Kemenkes, 2018).

Berdasarkan uraian data di atas, maka peneliti mengadakan penelitian tersebut untuk mengetahui hubungan kepatuhan ibu nifas terhadap pengetahuan manajemen laktasi pada ibu nifas di wilayah kerja Puskesmas Sebengkok.

\section{Metode}

Penelitian ini merupakan penelitian analitik dengan pendekatan cross sectional, yaitu mengetahui hubungan kepatuhan kunjungan ibu nifas terhadap manajemen laktasi di wilyah kerja Puskesmas Wilayah Sebengkok. Tarakan. Populasi dalam penelitian ini adalah seluruh ibu nifas yang melakukan kunjungan Nifas di Pusksemas Sebengkok pada bulan Maret tahun 2020 sebanayk 45 ibu nifas. Teknik pengambilan sampel dalam penelitian ini menggunkan total sampling. Untuk mendapatkan informasi dalam penelitian ini, peneliti menggunakan data primer. Alat yang digunakan untuk pengumpulan data dalam penelitian ini adalah kuesioner untuk mengetahui kepatuhan ibu nifas terhadap pengetahuan manajemen laktasi, sebanyak 30 soal dan terdapat data demografi dari responden. Analisis dalam penelitian ini menggunakan uji statistik chi Square (Masturoh \& Anggita, 2018).

\section{Hasil}

Karakteristik ibu nifas meliputi umur, pendidikan, pekerjaan dapat dilihat pada tabel 1 dibawah ini:

Tabel 1. Distribusi Frekuensi Responden Berdasarkan Umur, Pendidikan, Pekerjaan Tentang Pentingnya Kepatuhan Kunjungan Nifas Terhadap Pengetahuan Manajemen Laktasi di Puskesmas Sebengkok.

\begin{tabular}{lcc}
\hline Karateristik & $\begin{array}{c}\text { Jumlah } \\
(\mathbf{n})\end{array}$ & $\begin{array}{c}\text { Presentase } \\
(\mathbf{\%})\end{array}$ \\
\hline 1. Umur & & \\
$<20$ tahun & 8 & 17,7 \\
21 - 34 tahun & 30 & 66,7 \\
$>35$ tahun & 7 & 15,6 \\
\hline Total & $\mathbf{4 5}$ & $\mathbf{1 0 0 , 0}$ \\
\hline 2. Pendidikan & & \\
SD & 6 & 13,3 \\
SMP & 17 & 37,8 \\
SMA/SMK & 14 & 31,1 \\
Perguruan & 8 & 17,8 \\
Tinggi & & \\
\hline Total & $\mathbf{4 5}$ & $\mathbf{1 0 0 , 0}$ \\
\hline 3. Pekerjaan & & \\
IRT & 24 & 53,3 \\
Wiraswasta & 16 & 35,6 \\
PNS & 5 & 11,1 \\
\hline Total & $\mathbf{4 5}$ & $\mathbf{1 0 0 , 0}$ \\
\hline
\end{tabular}


Penilaian terhadap ibu nifas untuk mengetahui kepatuhan dalam kunjungan nifas dapat dilihat pada tabel 2 berikut:

Tabel 2. Distribusi Frekuensi Kepatuhan Ibu Nifas Terhadap Kunjungan Nifas di Puskesmas Sebengkok

\begin{tabular}{lcc}
\hline Kepatuhan & $\begin{array}{c}\text { Jumlah } \\
(\mathbf{n})\end{array}$ & $\begin{array}{c}\text { Presentase } \\
(\boldsymbol{\%})\end{array}$ \\
\hline Patuh & 39 & 86,7 \\
Tidak Patuh & 6 & 13,3 \\
\hline Total & $\mathbf{4 5}$ & $\mathbf{1 0 0 , 0}$ \\
\hline
\end{tabular}

Pengetahuan ibu nifas terhadap manajemen laktasi dapat dilihat pada tabel 3 berikut:

Tabel 3. Distribusi Frekuensi Berdasarkan Pengetahuan Manajemen Laktasi di Puskesmas Sebengkok

\begin{tabular}{lcc}
\hline Pengetahuan & $\begin{array}{c}\text { Jumlah } \\
(\mathbf{n})\end{array}$ & $\begin{array}{c}\text { Presentase } \\
(\boldsymbol{\%})\end{array}$ \\
\hline Baik & 32 & 71,1 \\
Cukup & 9 & 20,0 \\
Kurang & 4 & 8,9 \\
\hline Total & $\mathbf{4 5}$ & $\mathbf{1 0 0 , 0}$ \\
\hline
\end{tabular}

Kepatuhan kunjungan Nifas Terhadap

Pengetahuan Manajemen Laktasi pada ibu nifas dapat dilihat pada tabel 4 berikut:

Tabel 4. Distribusi Berdasarkan Kepatuhan Kunjungan Nifas Terhadap Pengetahuan Manajemen Laktasi di Puskesmas Sebengkok

\begin{tabular}{|c|c|c|c|c|c|c|c|c|c|c|}
\hline \multirow{3}{*}{$\begin{array}{c}\text { Kepa } \\
\text { tuhan }\end{array}$} & \multicolumn{6}{|c|}{ Pengetahuan } & \multirow{3}{*}{$\begin{array}{l}\text { To } \\
\text { tal } \\
(\mathrm{n})\end{array}$} & \multirow{3}{*}{$\%$} & \multirow{3}{*}{$\underset{\mathbf{2}}{\mathbf{X}}$} & \multirow{3}{*}{$\mathbf{P}$} \\
\hline & \multicolumn{2}{|c|}{ Kurang } & \multicolumn{2}{|c|}{ Cukup } & \multicolumn{2}{|c|}{ Baik } & & & & \\
\hline & (n) & $\%$ & $(\mathrm{n})$ & $\%$ & (n) & $\%$ & & & & \\
\hline \multirow{3}{*}{$\begin{array}{l}\text { Tidak } \\
\text { Patuh } \\
\text { Patuh }\end{array}$} & 3 & 6.7 & 1 & 2.2 & 0 & 0 & 4 & 8.9 & 15 & $\begin{array}{l}0 \\
\text {. }\end{array}$ \\
\hline & 3 & 67 & 12 & 266 & 26 & 578 & 11 & 0 & $\begin{array}{l}.0 \\
81\end{array}$ & 0 \\
\hline & & & & & & & & & & 1 \\
\hline Total & 6 & 13.3 & 13 & 28.9 & 26 & 57.8 & 45 & 100 & & \\
\hline
\end{tabular}

\section{Pembahasan}

1. Kepatuhan Ibu Nifas Terhadap Kunjungan Nifas di Puskesmas Sebengkok

Dari penelitian diatas didapatkan bahwa sebagaian besar reponden memiliki kepatuhan yang baik selama masa neifas dengan 3 kali melakukan kunjungan nifas yaitu (kunjungan nifas 16 jam-3 hari, kunjungan nifas 2 : 4-28 hari), kunjungan nifas 3 (29-42 hari) (tabel 2) yang dilakukan di Puskesmas Sebengkok. Hal ini di dukungung oleh penelitian lain bahwa kepatuhan kunjungan nifas didukung oleh beberapaa factor yaitu adanya penyedia layanan kesehatan, tingkat pendidikan, adanya komunikasi antara penyedia layanan dan ibu nifas dan adanya transportasi (Abraha et al., 2019)

2. Pengetahuan Manajemen Laktasi di Puskesmas Sebengkok

Berdasarkan tabel 3 menunjukan bahwa dari 45 responden, terdapat 32 ibu nifas $(71,1)$ mempunyai pengetahuan yang baik, dan 9 orang mempuntyai penegtahuan cukup (20\%) dan 4 ibu nifas memiliki penegtahuan yang kurang (8,9\%). Pengetahuan 
Gusriani Dkk. Kepatuhan Kunjungan Nifas Terhadap Pengetahuan Manajemen Laktasi Pada

Ibu Nifas Di Wilayah Kerja Puskesmas Sebengkok Kota Tarakan. Journal Of Borneo Holistic

Health, Vol.3, No. 1 Juni 2020 Hal 69-74

seseorang dapat dipengaruhi oleh factor eksternal dan internal. Penegtahuan dipengaruhi besar oleh tingkat pendidikan seseorang, dimana semakin tinggi pendidikan seseorang maka semakin luas pengetahuaanya. Namun, tidak mutlak seseorang yang berpendidikan rendah memiliki pengetahuan rendah. Sebab, setiap sesorang mengandung aspek positif dan negative. Kedua aspek ini akan mempengaruhi sikap mereka. Semakin banyak aspek positif dan objek maka akan memberikan sikap yang positif (Notoatmodjo \& Soekidjo, 2005).

\section{Hubungan kepatuhan kunjungan} nifas terhadap manajemen laktasi di

\section{Puskesmas Sebengkok}

Berdasarkan hasil perhitungan dengan menggunakan metode uji statistic, disimpulkan bahwa ada hubungan signifikan antara kepatuhan ibu melakukan kunjungan nifas dengan pengetahuan manajemen laktasi di Puskesmas Sebengkok Tarakan, dengan nilai koefisiensi kontingensi atau nilai $r$ $=0.501$ yang artinya keeratan antara dua variable mempunyai tingkat hubungan sedang.

Tabel 4 menunjukan bahwa sebanyak $26(57.8 \%)$ ibu nifas patuh melakukan kunjungan nifas dan memiliki pengetahuan yang baik tentang manajemen laktasi. Terdapat 12 $(2, .6 \%)$ ibu nifas yang patuh melakukan kunjungan nifas, memiliki pengetahuan cukup baik terkait manajemen laktasi dan terdapat masing-masing $3(6,7 \%)$ ibu nifas patuh dan tidak patuh melakukan kunjungan nifas dengan pengetahuan yang kurang terkait manajemen laktasi. Dukungan menyusui di dapatkan melalui kunjungan nifas yang dilakukan ibu. Kunjungan nifas memberikan banyak manfaat untuk ibu nifas, selain promosi kesehatan, dukungan konseling yang dilakukan bidan dalam manajemen laktasi memberikan pengaruh besar terhadap kesuksesan pemberian ASI (Masturoh \& Anggita, 2018)

\section{Kesimpulan}

Berdasarkan hasil penelitian yang telah dilakukan tentang kepatuhan kunjungan nifas terhadap penegtahuan manajemen laktasi di Puskesmas Sebengkok Kota Tarakan sebagian besar responden memilki kepatuhan kunjungan nifas sesuai standar yaitu tiga kali yaitu 39 (86,7\%), dan sebanyak 6 $(13,3 \%)$ ibu nifas tidak patuh untuk melakukan kunjungan nifas. Diperoleh 
Gusriani Dkk. Kepatuhan Kunjungan Nifas Terhadap Pengetahuan Manajemen Laktasi Pada

Ibu Nifas Di Wilayah Kerja Puskesmas Sebengkok Kota Tarakan. Journal Of Borneo Holistic

Health, Vol.3, No. 1 Juni 2020 Hal 69-74

juga sebanyak $26(57.8 \%)$ ibu nifas

patuh melakukan kunjungan nifas dan memiliki pengetahuan yang baik tentang manajemen laktasi. Terdapat $12(26,6 \%)$ ibu nifas yang patuh melakukan kunjungan nifas, memiliki pengetahuan cukup baik terkait manajemen laktasi. Berdasarkan $\mathrm{X}^{2}$ hitung $>X^{2}$ tabel dan $p<\alpha=0.001$ yang artinya ada hubungan signifikan antara kepatuhan ibu melakukan kunjungan nifas dengan pengetahuan manajemen laktasi di Puskesmas Sebengkok Tarakan.

\section{Referensi}

Abraha, T. H., Gebrezgiabher, B. B., Aregawi, B. G., Belay, D. S., Tikue, L. T., \& Reda, E. B. (2019). Factors associated with compliance with the recommended frequency of postnatal care services in four rural districts of Tigray region, north Ethiopia. Korean Journal of Family Medicine, 40(5), 329-334.

https://doi.org/10.4082/kjfm.18.0023

Biomedika, J. (2019). Persepsi ibu nifas terhadap pelayanan kunjungan nifas mother 's perception of the post partum visit services. 12(01), 93-99. https://doi.org/https://doi.org/10.31001 /biomedika.v12i1.383

Kemenkes. (2018). info DATIN (Pusat Data dan Informasi Kementrian RI). Kementerian Kesehatan RI, 1-7.

Masturoh, I., \& Anggita, N. (2018). METODE PENELITIAN KESEHATAN. Pusat Pendidikan Sumber Daya Manusia Kesehatan Badan Pengembangan Dan Pemberdayaan Sumber Daya Manusia Kesehatan.

Notoatmodjo, \& Soekidjo. (2005). Promosi Kesehatan. Rineka Cipta.

Nurbaeti, I., \& Budi Lestari, K. (2013). Efektivitas Comprehensive Breastfeeding Education terhadap Keberhasilan Pemberian Air Susu Ibu Postpartum. Jurnal Keperawatan Padjadjaran, $\quad$ vl(n2), 88-98. https://doi.org/10.24198/jkp.v1n2.4

Sokaraja, P., \& Banyumas, K. (2016). Kunjungan Nifas. 14(2), 59-64. 